\title{
AN AETIOLOGICAL STUDY ON SPONDYLOLYSIS FROM A BIOMECHANICAL ASPECT
}

\author{
N. ICHIKAWA, MD, * Y. OHARA, MD, " T. MORISHITA, MD, ${ }^{*}$ Y. TANIGUICHI, MD* \\ A. KOSHIKAWA, MD** and N. MATSUKURA, MD† \\ *Osaka City University, Medical School Orthopaedic Department, OSAKA, Japan \\ * *National Osaka Hospital, Orthopaedic Department, OSAKA, Japan \\ tNational Tanabe Hospital, Orthopaedic Department, TANABE, Japan
}

\begin{abstract}
The authors report clinical studies on lumbar disorders (clinical symptoms, $X$-ray findings) in athletes in various sports. The sport items were divided into three groups according to the main dynamic load applied to the lumbar region. As a result, over $60 \%$ of the athletes suffered from "lumbago", and among them spondylolysis reached the high rate of $27 \%$. Arising from these clinical observations, we performed biomechanical laboratory analyses on human cadaver material, axial compression and rotational bending. Our results suggest that the incidence of spondylolysis depends upon the extent and direction of the loads.
\end{abstract}

\section{INTRODUCTION}

The spinal column plays an essential role in active movement as well as in supporting the head and trunk. The main burden is on the lower lumbar vertebrae because they support the heavy trunk in its straight upright stance and provide balance in various directional movements. As a result, it is widely known that the lower lumbar vertebrae are susceptible to severe orthopaedic disorders.

Since 1959, the authors have been performing studies on lumbar disorders among 607 athletes drawn from various selected sports (Table 1). The incidence of lumbar disturbances in our study has now reached about $60 \%$. In X-ray photographs spondylolysis shows a high rate of $27 \%$, though not all of these athletes suffer from low back discomfort.

Depending upon the type of sports stress, it was considered that there might also be differences between the morphological changes and arrangement of the vertebrae, the clinical findings and $X$-ray photographs. Therefore, a statistical analysis was performed to determine if there were any correlation between vertebral $X$-ray findings and clinical symptoms. In addition we performed biomechanical experiments upon cadaver material to add support to this idea.

\section{CLINICAL STUDY}

\section{Materials and Methods}

The athletes investigated were divided into three groups according to the direction of the main dynamic loads applied to the lumbar region (Table I).

From the standpoint of lumbar function, the lumbar vertebrae can be divided into front and rear structural elements with the posterior longitudinal ligament as

\section{TABLE I}

Lumbar disturbances found in participants in several different sports

\begin{tabular}{|c|c|c|c|c|}
\hline Sport & $\mathbf{N}$ & $\begin{array}{l}\text { "Lumbago" } \\
\text { Present }\end{array}$ & $\begin{array}{l}\text { Lumbar } \\
\text { Index } \\
<80\end{array}$ & $\begin{array}{l}\text { Spondylolysis } \\
\text { Present }\end{array}$ \\
\hline \multicolumn{5}{|l|}{$\begin{array}{l}\text { GROUP } 1 \\
\text { Axial Stress }\end{array}$} \\
\hline Rugby Football & 101 & 76 & 3 & 17 \\
\hline Amer. Football & 23 & 14 & 0 & 4 \\
\hline Weight Lifting & 52 & 44 & 12 & 22 \\
\hline Judo & 87 & 68 & 8 & 25 \\
\hline \multicolumn{5}{|l|}{$\begin{array}{l}\text { GROUP } 2 \\
\text { Rotational Stress }\end{array}$} \\
\hline Baseball & 75 & 25 & 3 & 9 \\
\hline Basketball & 16 & 4 & 2 & 2 \\
\hline Soccer & 32 & 18 & 3 & 3 \\
\hline Boxing & 49 & 18 & 0 & 8 \\
\hline Volleyball & 15 & 11 & 0 & 3 \\
\hline Tennis & 16 & 7 & 0 & 4 \\
\hline Table Tennis & 6 & 2 & 0 & 1 \\
\hline \multicolumn{5}{|l|}{$\begin{array}{l}\text { GROUP } 3 \\
\text { Bending Stress }\end{array}$} \\
\hline Kendo & 63 & 26 & 3 & 11 \\
\hline $\begin{array}{l}\text { Swimming } \\
\text { Athletics }\end{array}$ & 36 & 19 & 2 & 5 \\
\hline $\begin{array}{l}\text { Gymnastics } \\
\text { Rowing }\end{array}$ & $\begin{array}{l}17 \\
19\end{array}$ & $\begin{array}{l}14 \\
15\end{array}$ & $\begin{array}{l}2 \\
0\end{array}$ & $\begin{array}{l}5 \\
6\end{array}$ \\
\hline TOTAL & 607 & 361 & 38 & 125 \\
\hline
\end{tabular}

the boundary between the two (Fig. 1).

The $X$-ray findings and the physical findings were classified as in Figs. 2 and 3 . The following items were investigated:

(1) Sports and X-ray findings

(2) Sports and physical findings 


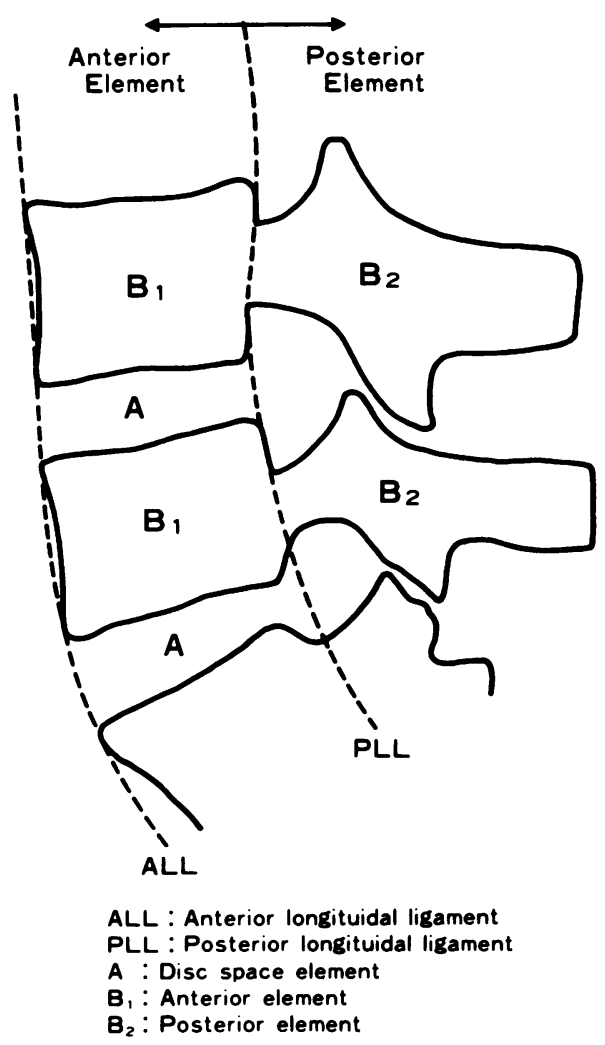

Fig. 1: Function of lumbar spine.

\section{Clinical results}

Following the results of the statistical investigations 0 of the various items concerning the athletes as mentioned previously, it is suggested that:

(1) There were differences in the organic findings in the $X$-ray photographs according to the types of sports (Figs. 2 and 3 ) and slight differences in the physical findings for the different types of sports (Fig. 3).

(2) A lumbar index below $80 \%$ was observed as a decrease in the height of the front structural element in group 1 (Table II).

(3) The incidence of spondylolysis varied in accordance with the types of sports, considered to be because of differences in such factors as the degree and direction of the load on the lumbar vertebrae in each sport (Table III).

(4) Ipsilateral spondylolysis progressed to bilateral spondylolysis after a few years, noted in follow-up investigations (Fig. 4). This finding encouraged us to perform the laboratory investigations upon cadaveric material, described below.

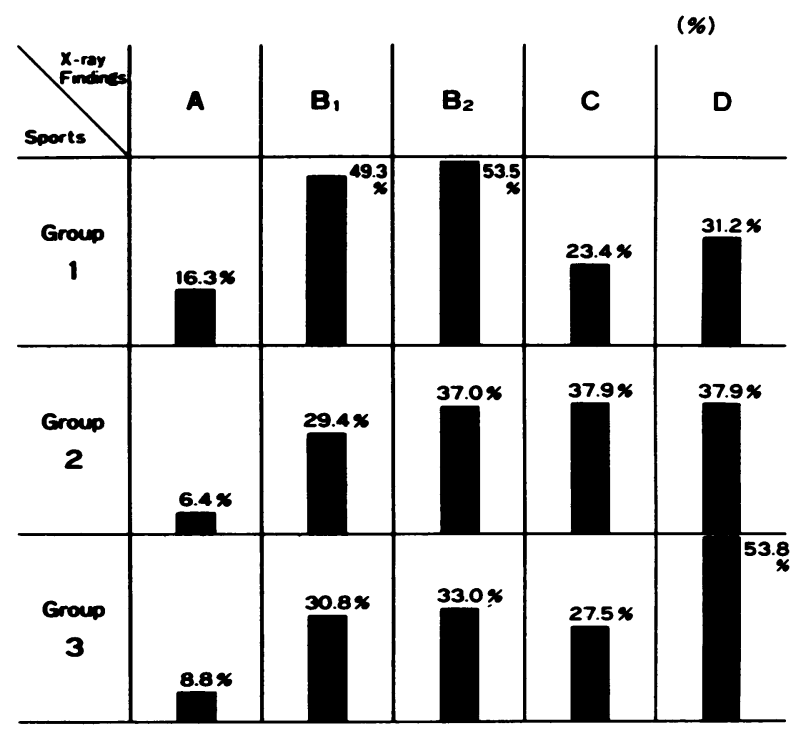

Comments

i) Narrowing of disc space

ii) Abnormal finding in anterior element

iii) Abnormal finding in posterior element

i) Abnormal alignment

of spine

ii) Instability of spine

ii) Anomaly

Group $1>$ Other

Group $1<$ Other

$X$-ray findings

A: Narrowing of disc space

$B_{1}$ : Anterior element

$\mathbf{B}_{\mathbf{2}}$ : Posterior element

C: Functional change of alignment

D: Anatomical change (anomaly)

Fig. 2: Sports and $X$-ray findings.

\section{EXPERIMENTAL STUDY}

\section{Material and Method}

Fresh human lumbo-pelvic blocks were utilised for the test (Table IV).

The thawed material was mounted in a steel box with methyl methacrylate, then placed in the apparatus for axial compression, anteroposterior bending and rotational stressing of the materials for the test (Fig. 5). Displacement transducers were constructed. For the measurement of the deflection, the displacement transducers were attached at the anterior and posterior parts of the spinal body and intervertebral disc, and for the pars interarticularis, they were set perpendicular to the direction in which spondylolysis usually develops (Fig. 6).

The loading test was repeated twice in succession, and average values were then calculated. 


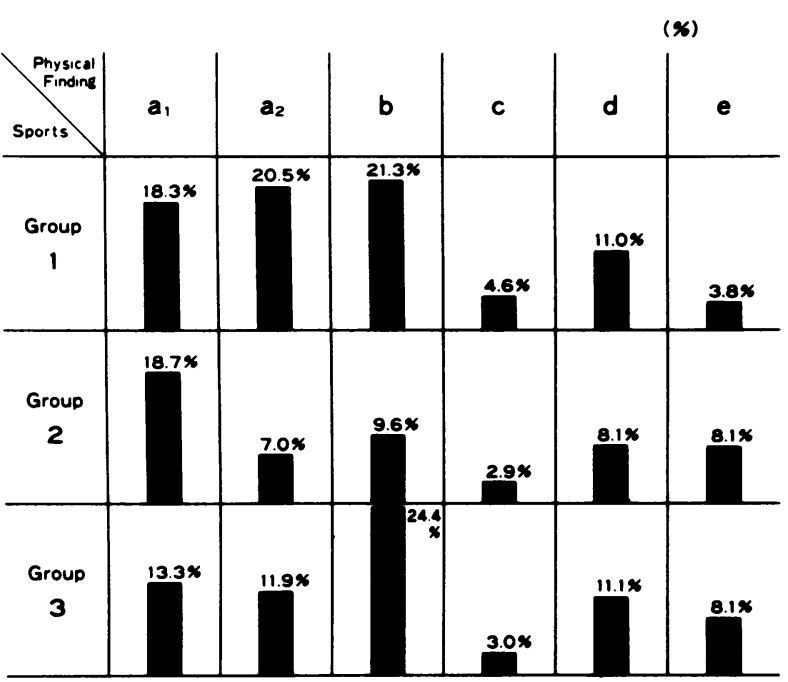

Comments

1) Tenderness of vertebral or spinal process Group $1>$ Other groups

3) Sports scoliosis Group 2 > Other groups

2) Abnormal neurological findings

Group $2<$ Other groups

Physical findings

$a_{1}$ : Tenderness (N. Cl. S points

$a_{2}$ : Tenderness

(vertebral body, spinal process)

b: Abnormal neurological findings

c: Restriction of spina

d: Pain on movement

e: Deformity of spine

(sport scoliosis)

Fig. 3: Sports and physical findings.

TABLE II

The incidence of lumbar index $<80$

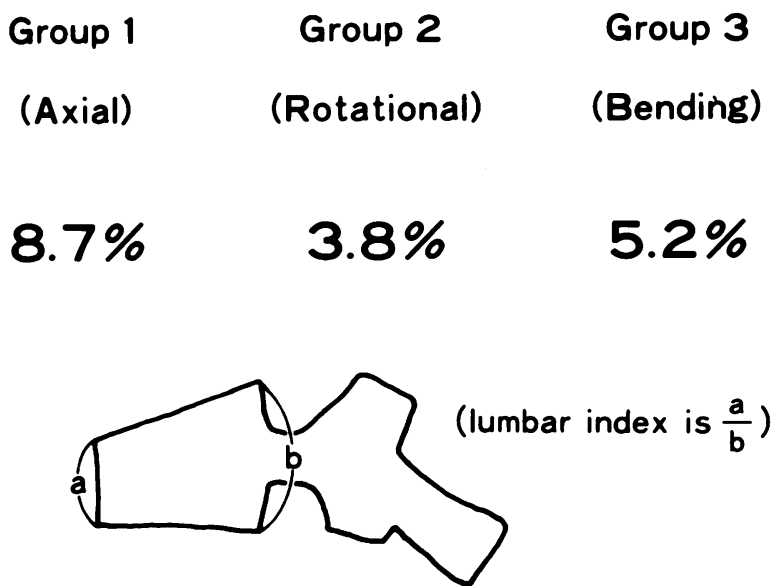

TABLE III

The incidence of spondylolysis

$\begin{array}{ccc}\text { Group } 1 & \text { Group 2 } & \text { Group 3 } \\ \text { (Axial) } & \text { (Rotational) } & \text { (Bending) }\end{array}$

$25.9 \%$

$14.4 \%$

$20.0 \%$

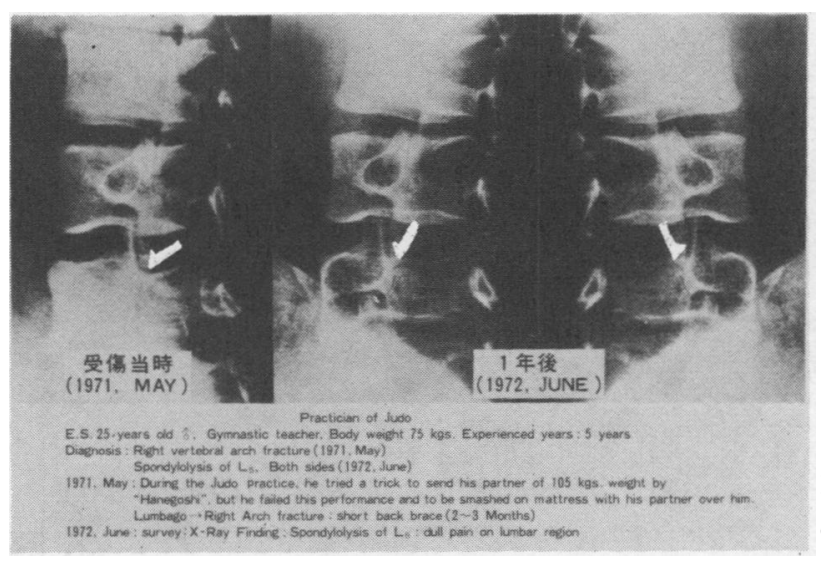

Fig. 4: Bilateral spondylolysis developed from ipsilateral spondylolysis.

\section{TABLE IV}

Post-mortem materials used in loading test

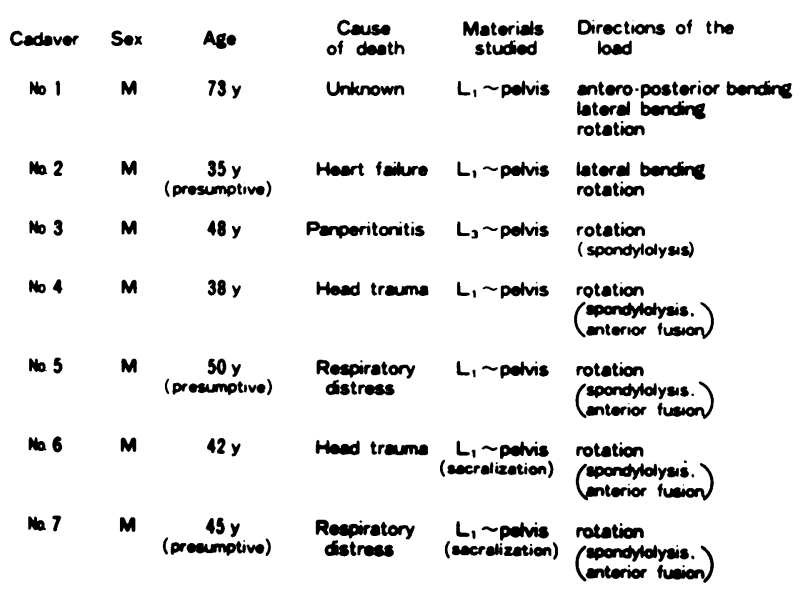



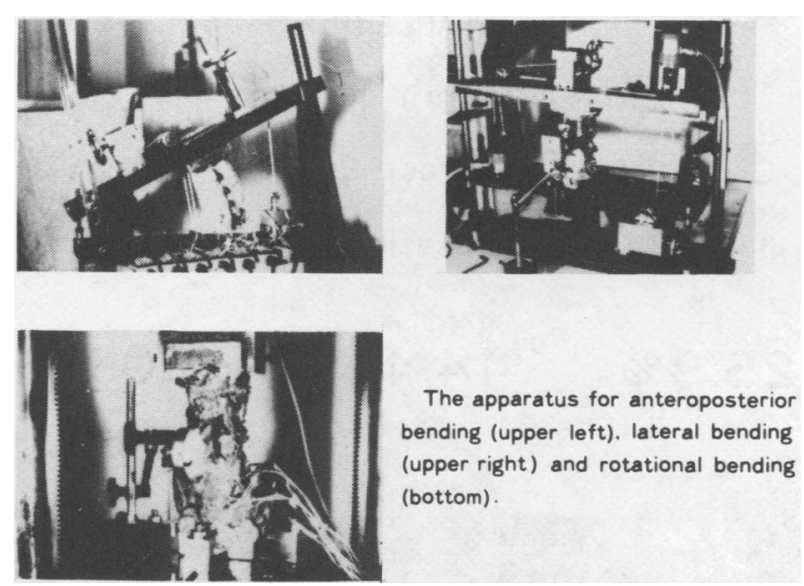

Fig. 5: The apparatus for anteroposterior bending (upper left), lateral bending (upper right) and rotational bending (bottom).

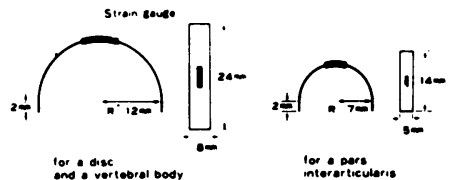

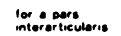
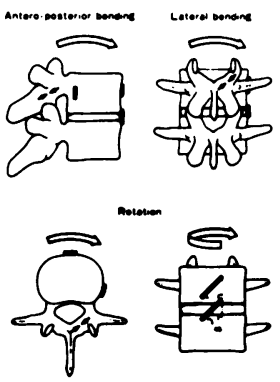

The new displacement transducers (left) and the position of the transducers on the spine (right).

Fig. 6: The new displacement transducers (left) and the position of the transducers on the spine (right).

\section{Experimental results}

Figure 7 shows the result of the axial compressive loading test. The anterior part of the spinal body shows maximum deformation at both the anterior and the posterior axial compression loading tests.

Figure 8 shows the result of the antero-posterior bending test. Under maximum loading in the neutral position of the spinal column, the deformation at each part increases linearly.

The pars interarticularis was excluded in the neutral position. In the position of extension of the spinal column the deformity value resembled that of compression.
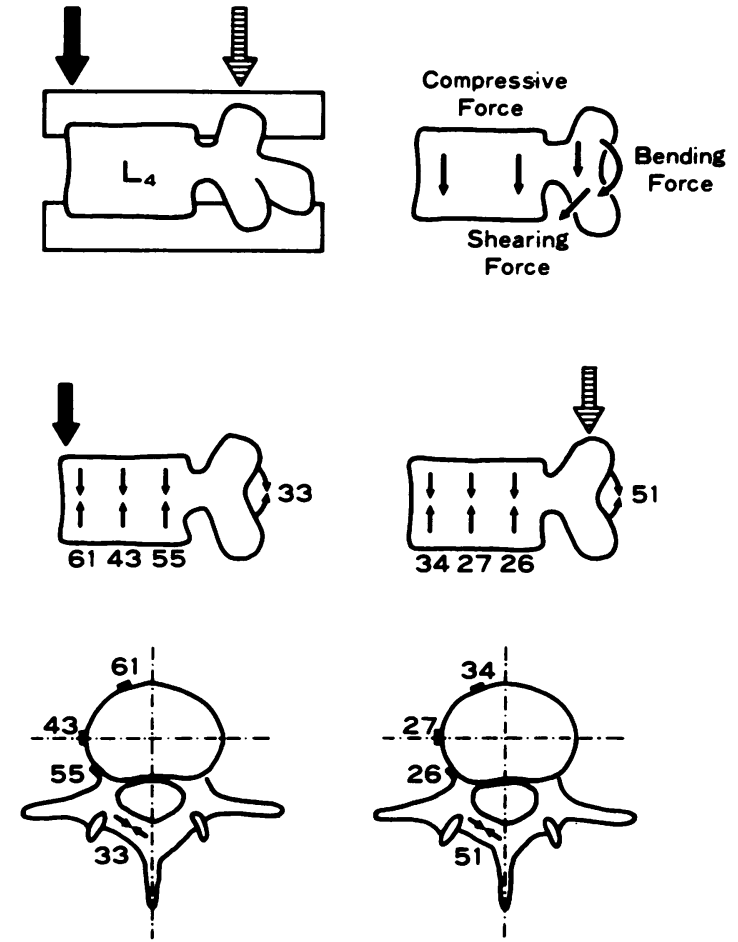

Fig. 7: Deformation under the max. load $(260 \mathrm{~kg} . \mathrm{f})$ ( $\mu m)$.

Figure 9 shows the result of the rotation. As the rotational angle increased, the deformity values at each point increased and as the axial compressive load increased the deformity value became markedly larger. Investigation on the amount of stress showed that the existing unilateral spondylolytic pars could extend to the other intact pars interarticularis in rotation of the spine and it showed high deformity value at the L5 (the fifth lumbar vertebrae) intact pars interarticularis (Fig. 10).

\section{DISCUSSION}

Clinical findings varied with the three different types of sports.

Both clinical and experimental results show that the anterior part of the spinal body sustained maximum deformity with the repetition of the axial compressive load (Fig. 11).

With regard to the spondylolysis, it developed in over $20 \%$ of all the athletes investigated. Of these $77 \%$ suffered from lumbar disturbances, and $23 \%$ did not. During our follow-up clinical investigation, one new case of spondylolysis was detected (Fig. 4). 


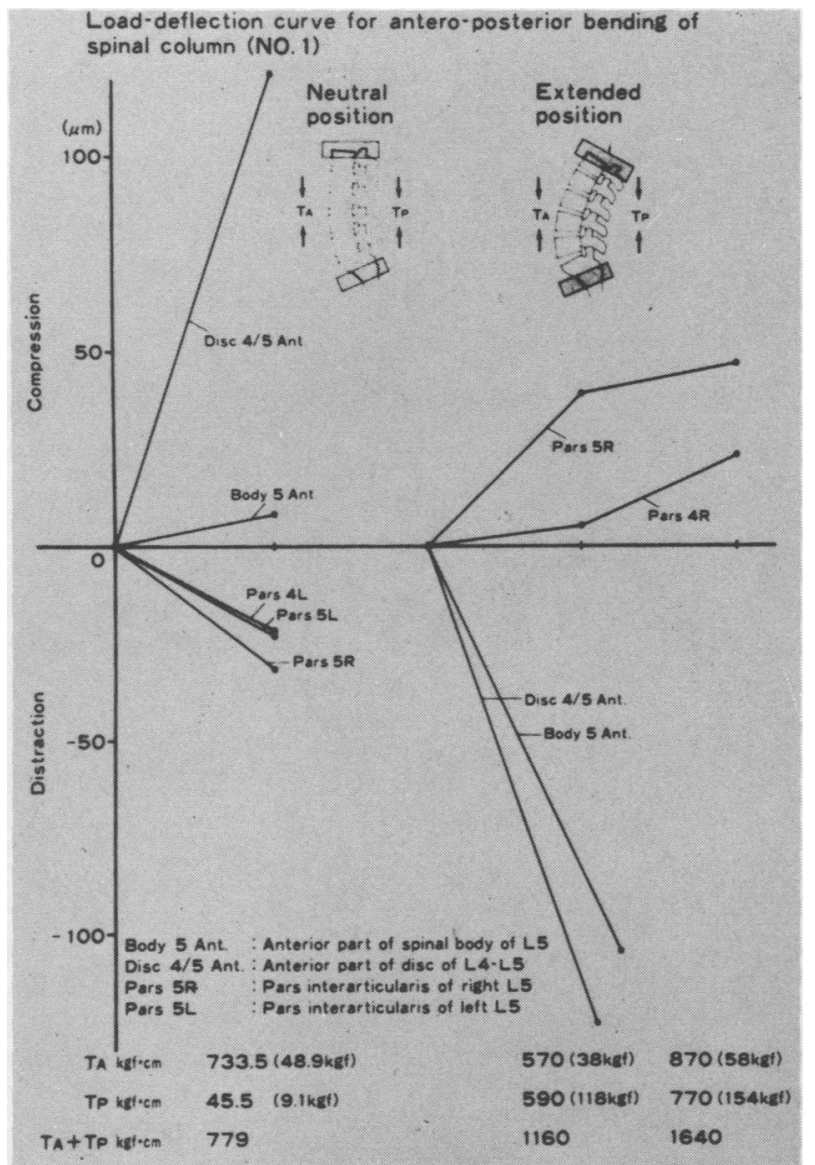

Fig. 8: Load-deflection curve for antero-posterior bending of spinal column (NO. 1).

This evidence shows that the aetiologically acquired spondylolysis can be divided into two types; one is acute fracture owing to major stress on one occasion and the other is the stress fracture (Fig. 12). Our evidence suggests that the incidence of spondylolysis depends upon the types of sports as stated above, and may be due to directional differences in the loading to the spinal column (Fig. 13).

In the antero-posterior loading test of the spinal column, the deformity of the pars interarticularis caused compressive strain in extension of the spinal column, and tensile strain in the neutral position. In one clinical case of spondylolysis, the X-ray finding showed the socalled Nathan's "pincers effect". We, furthermore, experienced one interesting clinical case of bilateral

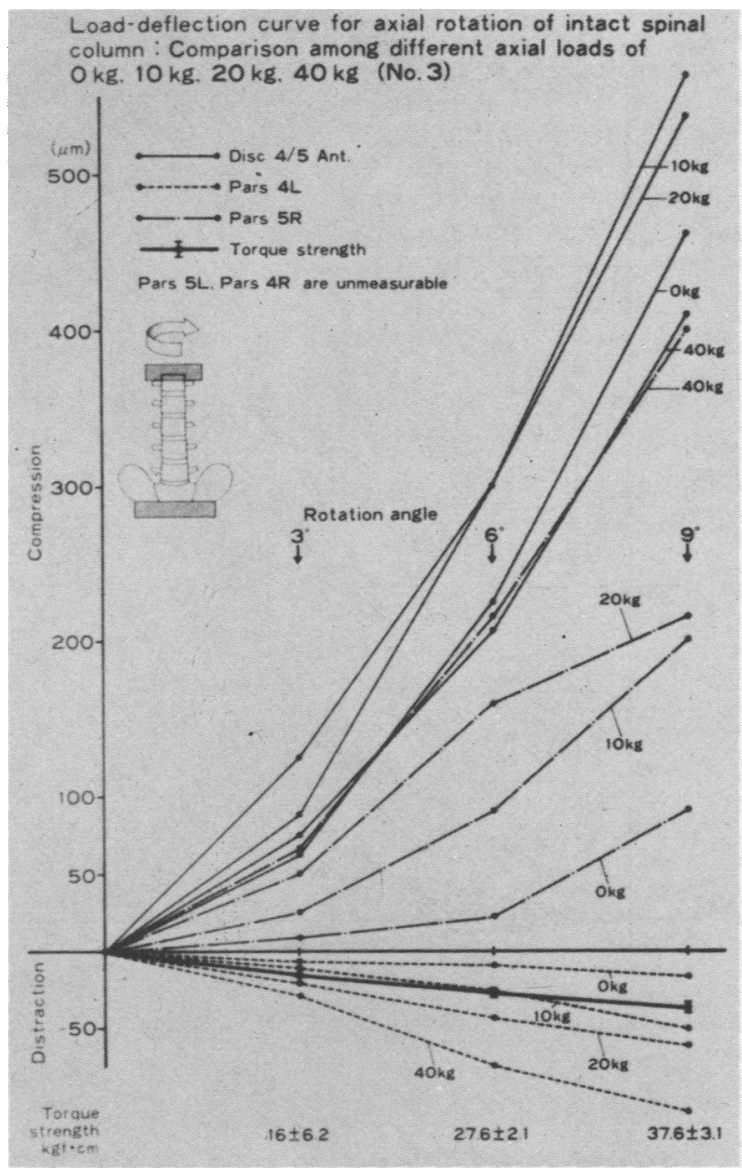

Fig. 9: Load-deflection curve for axial rotation of intact spinal column: Comparison among different axial loads of $0 \mathrm{~kg}, 10 \mathrm{~kg}, 20 \mathrm{~kg}, 40 \mathrm{~kg}$ (No. 3).

spondylolysis.

We investigated one case that showed sacralisation of L5, which showed that the maximum loading was shown on the L4 level pars interarticularis.

As stated above, it was confirmed both clinically and experimentally that various organic changes were made in the lumbar spinal column depending on the type of sport. As shown in Figure 14 an assumption was made on the correlation between these organic and functional changes, and lumbar pain, that the organic changes in the lumbar region, including the vertebral and soft tissue lead usually to functional disabilities affected by such additional factors as limitation of mobility, pain and severe functional disturbances that limit both sporting and working efficiency. 


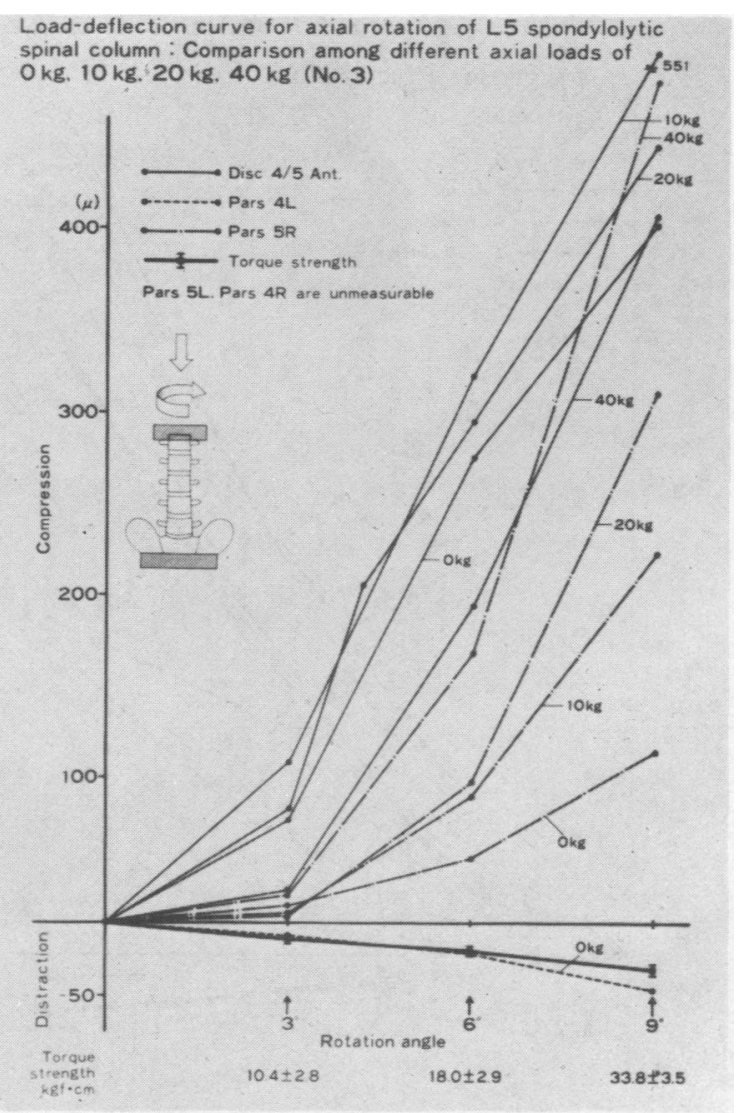

Fig. 10: Load-deflection curve for axial rotation of $\angle 5$ spondylolytic spinal column: Comparison among different axial loads of $0 \mathrm{~kg}, 10 \mathrm{~kg}, 20 \mathrm{~kg}, 40 \mathrm{~kg}$ (No. 3).
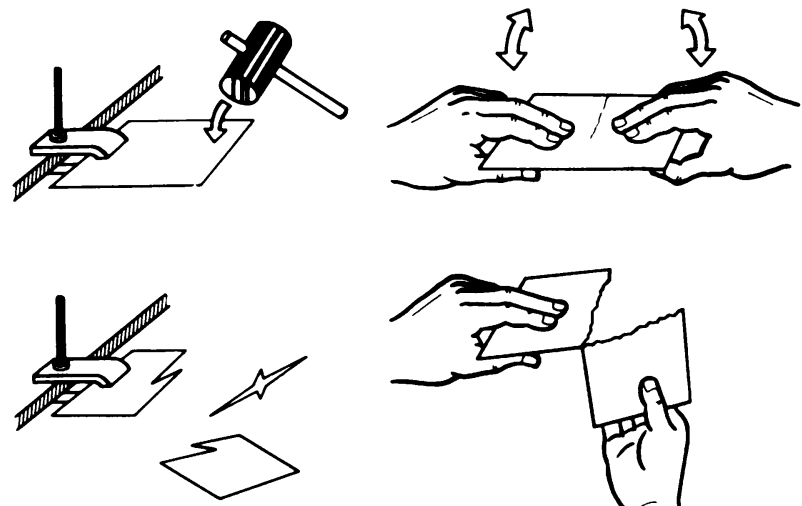

traumatic fracture

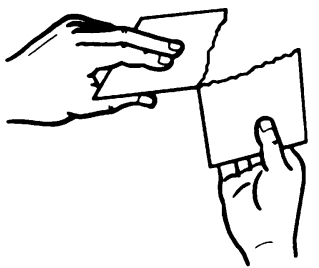

stress fracture

Fig. 12: The aetiology of spondylolysis

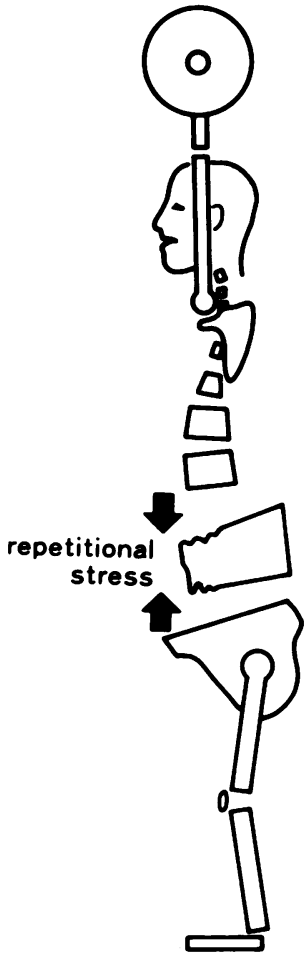

Fig. 11: The result of the repetitional stress on the vertebral body. 


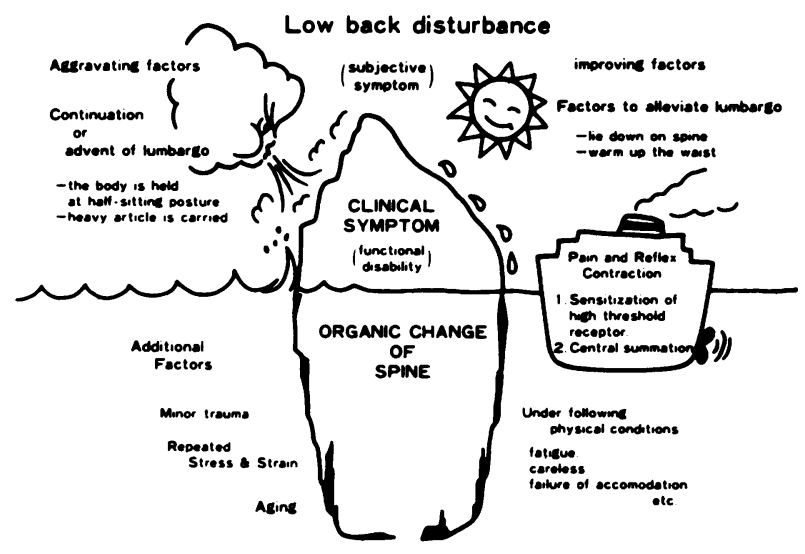

Fig. 14: Relation between lumbago and functional change of spine.

\section{BIBLIOGRAPHY OF RECOMMENDED READING}

Cyron, B. M., Hutton, W. C. and Troup, J. D. G., 1976 "Spondylolytic fractures". J.Bone and Joint Surg. 58-B: 462-466.

Farfan, H. F., Cossette, J. W., Robertson, G. H., Wellis, R. V. and Kraus, H., 1970 "The effects of torsion on the lumbar intervertebral joints: The role of torsion in the production of disc degeneration". J.Bone and Joint Surg. 52-A: 468-497.

Gregersen, G. G. and Lucas, D. B., 1967 "An in vivo study of axial rotation of the human thoracolumbar spine". J.Bone and Joint Surg. 49-A: 247-262.

Ichikawa, N., Hirohashi, K., Komatsu, K., Wakabayashi, W., Osada, A., Baba, Y., Watanabe, N., Koshimune, M., Kuroda, K., Matsuda, H., Kanbara, T., Maeda, T., 1974 "Lumbar lesion in athletes especially weight lifters". Clin. Orthop.Surg. 9: 140-148 (Japanese).

Ichikawa, N., Wakabayashi, W., Koshimune, M., Kuroda, K., Koshikawa, A., 1975 "Lumbar lesion in athletes especially concerning the aetiology of spondylolysis". Traum.Medicine 18: $931-937$ (Japanese).

Jackson, D. W., Wiltse, M. D. and Cirincione, R. J., 1976 "Spondylolysis in the female gymnast". Clin.Orthop. 117: 68-73.

Koshikawa, A., 1979 "A mechanical study on the developing factors of spondylolysis according to the deformation of human lumbar vertebrae under loading". J.Physical Fitness Japan 28: $56-72$ (Japanese).

Nathan, H., 1959 "Spondylolysis". J.Bone and Joint Surg. 41-A: 303-320.

Troup, J. D. G., 1977 "The aetiology of spondylolysis". 8-57-64. 